\section{No mean feet}

Pramod Karan Sethi, the inventor of a revolutionary artificial foot, regrets that he has not been able to pass his idealism on to young doctors. He talks to Dinesh Singhal and Samiran Nundy

It was pure chance that led Pramod Karan Sethi to take up orthopaedics. "In 1958 the Medical Council of India were to inspect Jaipur Medical College to see whether it was worthy of accreditation, but there was no department of orthopaedics. Iwho was trained as a general surgeon and had recently returned from the United Kingdom-was ordered by the principal to start one," Dr Sethi explains.

This act of expediency on the principal's part had more far reaching consequences than he could have envisaged, for Sethi went on to design a light, hard wearing, cheap artificial foot that transformed the lives of thousands of people in the subcontinent. As Sethi worked in the Rajasthan city of Jaipur, it became known as the Jaipur foot

Sethi, a 76 year old who has devoted his life to helping disadvantaged people, believes that it was because he had not trained as an orthopaedic surgeon that helped him produce something that was genuinely new.

"I think this made me look at the subject from a perspective different from a conventionally trained orthopaedic surgeon, who would probably repeat what his British boss had taught him. I looked for alternative methods of management which might be more suitable for our country."

Sethi found that patients with polio were being referred to Mumbai for limb braces. This, he thought, was stupid, because most patients could not afford the trip, and those who could often threw away the expensive braces when they returned to their villages because they were too heavy. When the patients were seen again they often had worse deformities than before.

"I decided to use local craftsmen to make similar braces which were lighter and cheaper. As we became more confident of our polio appliances we started thinking about how we might help our amputees who had had heavy, stiff, and shoe-covered artificial limbs fitted at the Army Limb

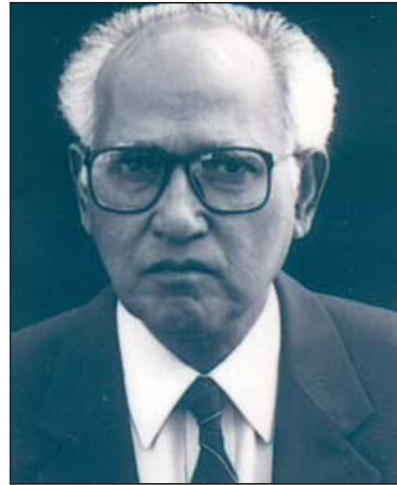

Pramod Karan Sethi: "I am disillusioned"

Centre in Pune... It was not possible for them to work in the fields or even enter their homes and kitchens, because our custom is to take off all footwear before coming indoors."

Sethi emphasises that in India people use floors for sleeping, sitting, eating, working, and worshipping and that without flexion at the knee or ankle wearers of artificial limbs cannot sit cross legged on the floor or squat in the toilet.

"I had seen a report by Dr G M Muller from Colombo, Sri Lanka, who had described a prosthesis in which a peg leg was covered by a rubber, foot-like cover so that the wearer could work in the paddy fields in water. So I got a local craftsman to make a foot of vulcanised rubber. This was too heavy and stiff, so we modified the design by filling the shell with sponge rubber to make it lighter and then placed a stiff piece for the metatarsals. Later we added microcellular rubber for the heel and cut wedges at its upper end to make a universal joint. A patient's brother then dyed the rubber to an Indian skin colour, and this became the Jaipur foot."

The foot is now tailor made in front of the user in 45 minutes. Each foot costs about 50 rupees (£0.60; \$1.10; €0.95), while the below-the-knee prosthesis-the Jaipur limb with a light aluminium calf-costs 150 rupees. Wearing this limb the user can work in the fields, climb trees, pull rickshaws, walk on uneven ground, or even perform traditional dance.

"I found that unlike in Western countries, where the majority of amputees are old and have vascular disease, most of our patients are young migrant labourers from eastern Uttar Pradesh and Bihar who have had their amputations after falling off our overcrowded trains on their way to find seasonal work during the Punjab harvest."

Millions of Jaipur limbs have been made locally and are used in Cambodia, Vietnam, Afghanistan, and Africa, where war injuries and now land mines are the most common causes of limb loss. In fact, production of Jaipur limbs often overtakes production of other models when they are introduced into a country. For example in Vietnam, where Sethi was invited to set up a centre, within a month his outfit was making more than all the other centresfrom Britain, the United States, France, and Germany, combined.

His team did a study in Jaipur, funded by the Indian Council of Social Science Research, to compare limbs produced by traditional craftsmen with those produced by professionally trained people working in specialised workshops. "The craftsmen had twice the output for half the investment, provided a superior product, and

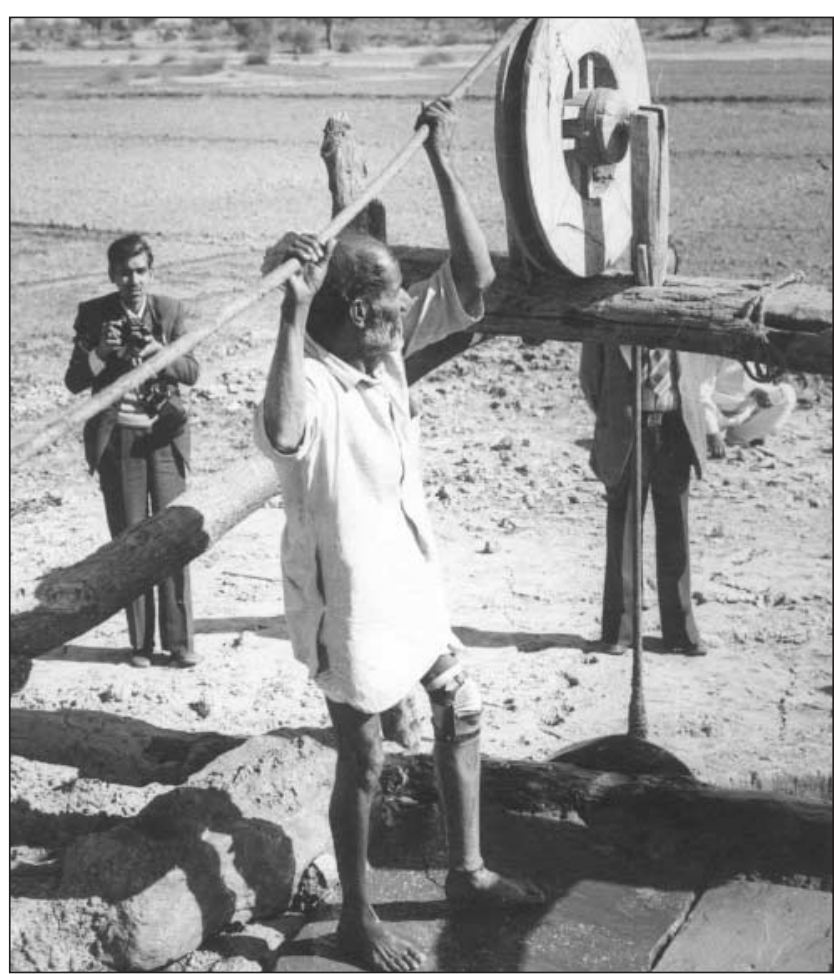

Before the introduction of the Jaipur limb (seen above), amputees were often unable to work in the fields with the prostheses available achieved greater patient satisfaction," he said

Despite national and international recognition, Sethi is not a happy man. He feels that present day students have been seduced by technology, which has raised the costs of health care.

"Doctors now don't listen to patients any more but rely on the results of laboratory tests. Our patients are being dehumanised."

$\mathrm{He}$ is also staggered by the extent of corruption in medicine in India, in which unnecessary investigations, overtreatment, and kickbacks from proliferating computed tomography and magnetic resonance imaging facilities are the norm.

"I am disillusioned. The greatest influences in my life were my father, who was a professor of physics at Benares Hindu University, and my medical teacher in Agra, Dr G N Vyas. They emphasised that the most important personal qualities were scholarship, simplicity, sacrifice, and service to the nation. I have often advised our young doctors not to rush to make a lot of money-the gratitude of the patient should be enough. But my main regret is that $I$ have not been able to pass on my ideology to them."

Dinesh Singhal and Samiran Nundy New Delhi by Western standards and blinded 